\title{
Comparison Study
}

\section{e Comparisons of Lesion Volumes and Shapes Produced by a Radiofrequency System with a Cooled, a Protruding, or a Monopolar Probe}

David L. Cedeño, PhD 1,2, Alejandro Vallejo, $\mathrm{HS}^{1,3}$, Courtney A. Kelley, BS ${ }^{1,2}$, Dana M. Tilley, PhD ${ }^{1,2}$, and Nitesh Kumar, $\mathrm{BS}^{2}$

From: 'Millennium Pain Center, Bloomington, Illinois; ${ }^{2}$ llinois Wesleyan University, Bloomington, Illinois; 3 University of Illinois at Urbana-Champaign, Champaign, Illinois

Address Correspondence: David L. Cedeño, PhD Millennium Pain Center 2406 E. Empire St

Bloomington, IL 61704

E-mail: dcedeno@ millenniumpaincenter.

Disclaimer: DLC, $\mathrm{AV}, \mathrm{CAK}$, and DMT are employees of Millennium Pain Center, which funded the study. Equipment used in the study was loaned from Halyard Health Inc.

Manuscript received: 12-10-2016

Revised manuscript received: o1-30-2017 Accepted for publication: 03-13-2017

Free full manuscript: www. painphysicianjournal. com
Background: Radiofrequency (RF) ablation for denervation has been utilized for decades in chronic pain management. This relies on the proper targeting of the affected nerve which may be obtained by creating an ablation lesion with a shape and volume that optimizes targeting. Various systems designed to improve lesion size are available. These include cooling the active tip (cooled-RF) and protruding the RF electrode outside the active tip (PERF).

Objectives: This study compares lesion volumes of 3 commercially available RF systems: cooled-RF, " $\mathrm{V}$ " shaped active cannula and protruding electrode (18 g and $20 \mathrm{~g}$ ), and monopolar RF (MRF; $16 \mathrm{~g}, 18 \mathrm{~g}$, and $20 \mathrm{~g}$ ).

Study Design: Ex vivo study using clinically relevant conditions.

Setting: Biophysical laboratory in an academic institution.

Methods: RF ablation lesions were generated in additive-free chicken breast specimens $(n=10)$ with the RF probes fully inserted in them. For cooled RF, a $17 \mathrm{~g}$ probe (4 mm active tip) was used. RF was applied for 150 seconds at $60^{\circ} \mathrm{C}$. PERF was applied using $18 \mathrm{~g}$ or $20 \mathrm{~g}$ introducers ( $10 \mathrm{~mm}$ active tip) for either 90 or 150 seconds at $80^{\circ} \mathrm{C}$. For MRF ablation, introducers diameter were $16 \mathrm{~g}, 18 \mathrm{~g}$, or $20 \mathrm{~g}$ (10 mm active tip), while RF was applied for 90 seconds at $80^{\circ} \mathrm{C}$. Tissues were dissected through the midpoint of the lesion, and measurements of the longitudinal, transversal, and depth lengths were taken and used to calculate the lesion volume. Measurements from the distal edge in the transverse and longitudinal directions were also recorded. One-way ANOVA was used to determine statistical significance between volume means ( $P$ $<0.05)$.

Results: Mean lesion volume with cooled RF $\left(595 \mathrm{~mm}^{3}\right)$ is significantly larger than any other mean volume measured. The second largest volume is produced with MRF using a $16 \mathrm{~g}$ introducer $\left(360 \mathrm{~mm}^{3}\right)$, which is significantly larger than those obtained with $18 \mathrm{~g}$ or $20 \mathrm{~g}$. This is also significantly larger than the one obtained with PERF using an $18 \mathrm{~g}$ introducer. Mean lesion volume produced with PERF $\left(80^{\circ} \mathrm{C}\right.$ for 90 seconds) and an $18 \mathrm{~g}$ diameter tip $\left(215 \mathrm{~mm}^{3}\right)$ is significantly larger than the respective one produced with MRF $\left(169 \mathrm{~mm}^{3}\right)$. Increasing lesioning time to 150 seconds significantly increases the volume $\left(283 \mathrm{~mm}^{3}\right)$. Using a $20 \mathrm{~g}$ tip produces the smallest lesions at $80^{\circ} \mathrm{C}$ for 90 seconds with either PERF or MRF, although a lesioning time of 150 seconds makes it significantly larger $\left(207 \mathrm{~mm}^{3}\right)$.

Limitations: The study is ex vivo and therefore does not account for the dynamic effects of the anatomy and physiology of a living organism.

Conclusions: The results indicate that the lesion produced with a cooled-RF system (17 $\mathrm{g}, 4 \mathrm{~mm}$ tip) is significantly larger than that produced with either of the other systems trialed $(18 \mathrm{~g}$ or $20 \mathrm{~g}, 10 \mathrm{~mm}$ active tip protruding electrode or $16 \mathrm{~g}, 18 \mathrm{~g}$, or $20 \mathrm{~g}$ monopolar electrode). Interestingly, a $16 \mathrm{~g}, 10 \mathrm{~mm}$ active tip monopolar electrode produced a larger lesion than the one produced with the $18 \mathrm{~g}$ protruding electrode.

Key words: Radiofrequency, ablation, lesion shape, lesion size, cooled-RF, protruding electrode RF, monopolar RF

Pain Physician 2017; 20:E915-E922 
$\mathrm{R}$ adiofrequency (RF) denervation to treat painful conditions was first introduced by Kirshner (1), in 1931, for patients with trigeminal neuralgia. Since then, this therapy has been used widely for the treatment of low back pain and joint pain (2-7), although there is still clinical work that needs to be done to fully prove its efficacy. Fundamental to the understanding of the lesions generated by RF is the high current density concentrated in close proximity to the targeted sensory nerve. When a RF current is applied via a monopolar electrode (ME) probe inserted through an insulated needle with an active exposed distal tip, ions in surrounding tissues create friction leading to an increase in temperature around the active tip $(8,9)$.

Considering the small size and variable location of sensory nerves, the lack of visualization of the targeted structures, and the limited effective radius of the lesion, consistent results would require electrode placement within 1 to $2 \mathrm{~mm}$ of the nerve (10). Consequently, heating a wide volume of tissue and affecting a larger length of the targeted nerve will improve success rate and duration of relief $(10,11)$. The size of the ablation produced by a ME probe is dependent on several factors including length and gauge of the active tip, current density, and duration of application of the RF current (10-13). In order to increase the size of a lesion produced with a ME probe, alternative probe designs have been introduced. Cooled RF is a system in which the active tip is watercooled in order to avoid excessive branding around the probe and increase the size of the lesion. Alternatively, a protruding electrode and active tip cannula have been combined to produce a "V" shaped zone in which the lesion develops and produces a larger lesion when compared with that produced by a ME probe and an introducer of equivalent gauge and length.

The current ex vivo study was designed to compare the lesion volume of 3 different available RF systems: cooled RF (CRF) (17 g), "V" shaped active cannula and protruding electrode (PE) (18 g and $20 \mathrm{~g}$ ), and monopolar RF (16 g, $18 \mathrm{~g}$, and $20 \mathrm{~g})$. Based on information provided by the manufacturers of these systems, it is hypothesized that cooled-RF will provide the largest lesion volume, followed by RF ablation using the PE and $18 \mathrm{~g}$ active cannula, and finally monopolar RF using a $16 \mathrm{~g}$ tip.

\section{Methods}

\section{Lesion Size Comparisons}

Three RF systems capable of producing therapeutic lesions were compared in this study. These included systems utilizing a cooled probe, a PE probe, and a ME probe. CRF was performed using a water-cooled 100 $\mathrm{mm}$ probe with a $17 \mathrm{~g}, 4 \mathrm{~mm}$ active tip (CRK-17-1004, Halyard Health, Alpharetta, GA, USA) at $60^{\circ} \mathrm{C}$ for 150 seconds. RF was applied using a Kimberly-Clark generator (PMG-115-TD). RF lesions using a PE probe utilized one of 2 different cannulas designed to protrude the RF electrode at the tip (Venom ${ }^{\circledR}$, Stryker, Kalamazoo, MI, USA). These consisted of either one with a $20 \mathrm{~g}(0.91 \mathrm{~mm})$ or $18 \mathrm{~g}(1.27 \mathrm{~mm})$ outer diameter. In both cases, a $10 \mathrm{~mm}$ active tip was used with a $100 \mathrm{~mm}$ RF electrode. RF was applied using a Stryker generator (MultiGen 406-900) at $80^{\circ} \mathrm{C}$ for either 90 seconds or 150 seconds. This generator provides a pre-heating ramping period in which current is applied for approximately 15 seconds until the target temperature is achieved. Lesions were also produced using monopolar probes $(100 \mathrm{~mm})$ with cannula having outer diameters of $20 \mathrm{~g}, 18 \mathrm{~g}$ (Stryker), or $16 \mathrm{~g}$ (1.65 mm, Halyard) and $10 \mathrm{~mm}$ active tips. In order to compare the effect of a generator of choice, RF was applied with either a Kimberly-Clark generator or a Stryker generator using an $18 \mathrm{~g}$ and a $20 \mathrm{~g}$ monopolar probe.

All lesions were produced in chicken breast that was free of any additives (Bloomington Meats, Bloomington, IL, USA). No fluids were injected into the breast prior to ablation. The initial temperature of the chicken breast was $21-29^{\circ} \mathrm{C}$, as measured by the thermocouple built in each electrode.

The cannula and probe of each lesion-producing system were introduced into the tissue perpendicular to the grounding pad (Fig. 1) which was placed underneath the specimen.

After ablation was completed, the tissue was sliced with a sharp blade through the midpoint along the probe entry to expose the lesion. The maximum longitudinal (L), transversal ( $T$ ), and depth (D) lengths were measured, to the nearest $0.05 \mathrm{~mm}$, using a Vernier caliper (Omega). The depth was obtained by slicing the 2 halves previously obtained (Fig. 2) and combining the measurements on each half lesion.

Measurements were taken by the same operator who had been previously trained to provide consistent and reproducible technique. These lengths were used to calculate lesion volumes (V) according to the following equation, which models the volume of either a sphere or an ellipsoid: $V=\pi / 6 \times T \times L \times D$

Other measurements obtained were the length from the distal edge to the cannula in the transverse 

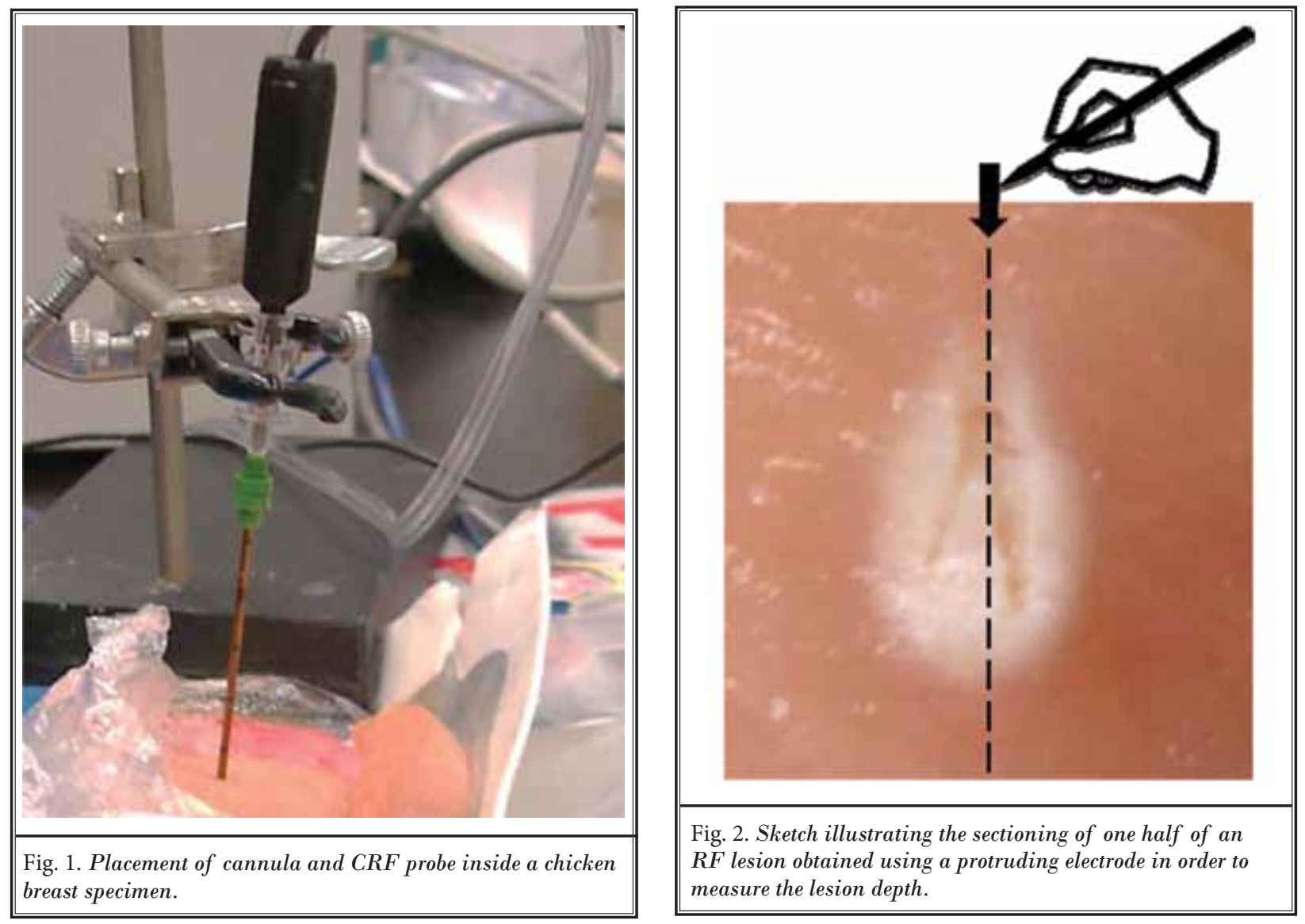

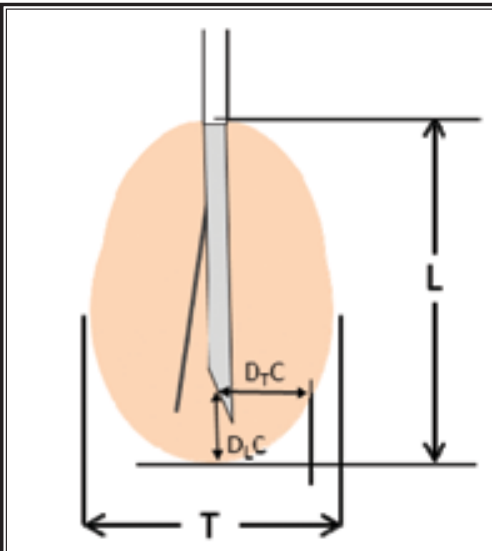

PE Probe

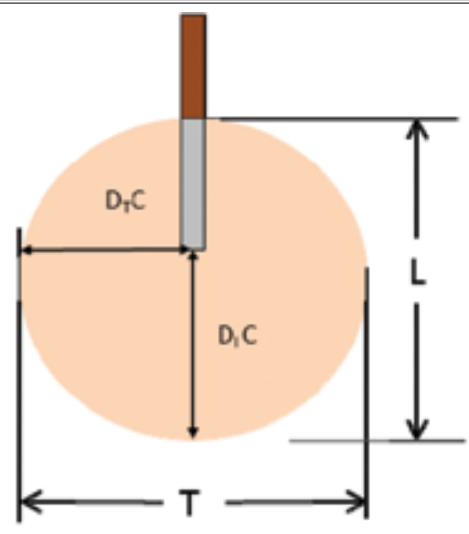

Cooled Probe

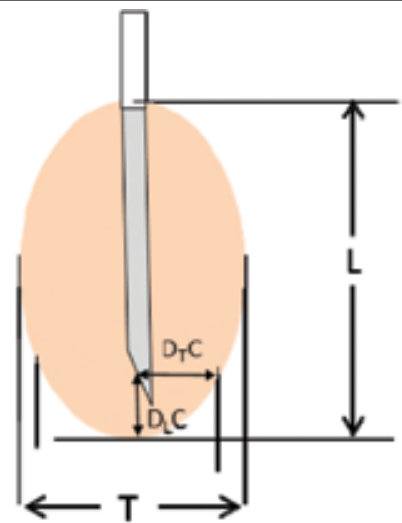

Monopolar Probe

Fig. 3. A sketch of the lengths experimentally measured for a lesion obtained using a particular probe.

direction $\left(D_{T} C\right)$, and the length from the distal edge to the cannula in the longitudinal direction $\left(D_{L} C\right)$ as illustrated in Fig. 3.

\section{Lesion Propagation}

Imaging sequences of lesions produced by CRF $(17 \mathrm{~g})$ or a PE probe (18 g) were obtained by inserting the respective probes slightly below the surface 
of the chicken tissue and setting a recording using an infrared (IR) camera (FliR i3, Flir Systems, Wilsonville, OR, USA) simultaneously with a visible camera (CyberShot, Sony America, San Diego, CA, USA). The IR camera was calibrated to record in the 23 to $86^{\circ} \mathrm{C}$ range, while pictures were recorded manually at about $3-5$ second intervals.

\section{Data Analysis}

Ten experiments were performed for each of the conditions tested using either cooled, PE, or ME probes. Measurements of $L, T$, and $D$ lesion dimensions were recorded in each experiment and used to calculate the lesion volume of each lesion. One-way ANOVA statistical test (Sigma-Plot 12.5, Systat Software, San Jose, California) was used to compare the multiple average lesion volumes obtained by using the CRF, PE, and ME probes under the conditions specified above. Holm-Sidak posthoc analysis was used for independent pairwise group comparisons. Significant differences were established when $P \leq 0.05$.

\section{Results}

\section{Lesion Volumes}

Table 1 summarizes the average length dimensions and lesion volumes. Figure 4 provides a graphical comparison of the mean lesion volumes among the 8 different conditions tested.
The mean lesion volume produced with $\mathrm{CRF}$ at $60^{\circ} \mathrm{C}$ for 150 seconds was significantly larger $(P<0.001)$ than that obtained using either of the other probes and lesioning conditions. The second largest mean lesion was produced with a $16 \mathrm{~g} \mathrm{ME}$ probe at $80^{\circ} \mathrm{C}$ for 90 seconds, which is significantly larger $(P<0.001)$ than the mean lesions obtained by using $18 \mathrm{~g}$ and $20 \mathrm{~g}$ ME probes, regardless of the RF generator used to produce them. Mean lesion size obtained with an $18 \mathrm{~g} \mathrm{PE}$ probe at $80^{\circ} \mathrm{C}$ for 90 seconds is significantly larger $(P<0.011)$ than the lesion size obtained with an $18 \mathrm{~g} \mathrm{ME}$ probe under similar lesioning conditions. The mean lesion volume produced by a $20 \mathrm{~g} \mathrm{PE}$ probe at $80^{\circ} \mathrm{C}$ for 90 seconds, although tend to be larger, was not significantly larger than the mean lesion produced by a $20 \mathrm{~g}$ ME probe. Longer lesioning time (150 seconds) while using a PE probe at $80^{\circ} \mathrm{C}$ contributed to a significant increase in lesion volume, either with an $18 \mathrm{~g}$ probe or a $20 \mathrm{~g}$ probe $(P<0.002$ and $P<0.012$, respectively). Indeed, lesioning with a $P E$ probe at $80^{\circ} \mathrm{C}$ for 150 seconds produce lesions that are significantly larger $(P<0.001)$ than any other lesioning produced with a $20 \mathrm{~g}$ probe (protruding or monopolar) and an $18 \mathrm{~g}$ monopolar probe.

\section{Lesion Propagation: CRF vs PERF}

Thermographic visualization of the evolution of RF lesions resulting from using a PE or cooled probe are shown in Fig. 5. The protruding electrode RF (PERF) sequence includes a pre-heating period that is part of the

Table 1. Average length measurements* and lesion volumes**.

\begin{tabular}{|c|c|c|c|c|c|c|}
\hline Method & $\mathbf{T}$ & $\mathbf{L}$ & D & $\mathbf{D}_{\mathrm{T}} \mathbf{C}$ & $\mathbf{D}_{\mathrm{L}} \mathbf{C}$ & $\mathbf{V}$ \\
\hline $\begin{array}{l}\text { CRF } 17 \mathrm{~g} \\
\left(60^{\circ} \mathrm{C}, 150 \mathrm{~s}\right) \\
\end{array}$ & $\begin{array}{c}11.2 \\
(10.5-11.9) \\
\end{array}$ & $\begin{array}{c}10.7 \\
(9.7-11.7) \\
\end{array}$ & $\begin{array}{c}9.5 \\
(9.0-10.0) \\
\end{array}$ & $\begin{array}{c}4.9 \\
(4.5-5.3) \\
\end{array}$ & $\begin{array}{c}4.2 \\
(3.5-4.9) \\
\end{array}$ & $\begin{array}{c}595 \\
(515-675) \\
\end{array}$ \\
\hline $\mathrm{ME} 16 \mathrm{~g}, \mathrm{KC}\left(80^{\circ} \mathrm{C}, 90 \mathrm{~s}\right)$ & $\begin{array}{c}7.4 \\
(7.1-7.7) \\
\end{array}$ & $\begin{array}{c}12.9 \\
(12.0-13.8) \\
\end{array}$ & $\begin{array}{c}7.3 \\
(6.8-7.8) \\
\end{array}$ & $\begin{array}{c}3.0 \\
(2.8-3.2) \\
\end{array}$ & $\begin{array}{c}2.4 \\
(1.9-2.9) \\
\end{array}$ & $\begin{array}{c}360 \\
(321-399) \\
\end{array}$ \\
\hline PE $18 \mathrm{~g}\left(80^{\circ} \mathrm{C}, 150 \mathrm{~s}\right)$ & $\begin{array}{c}7.2 \\
(6.8-7.6) \\
\end{array}$ & $\begin{array}{c}12.2 \\
(11.4-13.0) \\
\end{array}$ & $\begin{array}{c}6.2 \\
(5.8-6.6) \\
\end{array}$ & $\begin{array}{c}2.4 \\
(2.2-2.6) \\
\end{array}$ & $\begin{array}{c}2.2 \\
(2.0-2.4) \\
\end{array}$ & $\begin{array}{c}283 \\
(252-314) \\
\end{array}$ \\
\hline PE $18 \mathrm{~g}\left(80^{\circ} \mathrm{C}, 90 \mathrm{~s}\right)$ & $\begin{array}{c}6.9 \\
(6.5-7.3) \\
\end{array}$ & $\begin{array}{c}11.7 \\
(11.1-12.3) \\
\end{array}$ & $\begin{array}{c}5.1 \\
(4.7-5.5) \\
\end{array}$ & $\begin{array}{c}2.5 \\
(2.2-2.8) \\
\end{array}$ & $\begin{array}{c}1.7 \\
(1.5-1.9) \\
\end{array}$ & $\begin{array}{c}215 \\
(189-241) \\
\end{array}$ \\
\hline PE $20 \mathrm{~g}\left(80^{\circ} \mathrm{C}, 150 \mathrm{~s}\right)$ & $\begin{array}{c}6.3 \\
(5.8-6.8) \\
\end{array}$ & $\begin{array}{c}12.1 \\
(11.2-13.0) \\
\end{array}$ & $\begin{array}{c}5.3 \\
(5.0-5.6) \\
\end{array}$ & $\begin{array}{c}2.5 \\
(2.2-2.8) \\
\end{array}$ & $\begin{array}{c}2.1 \\
(1.8-2.5) \\
\end{array}$ & $\begin{array}{c}207 \\
(183-231) \\
\end{array}$ \\
\hline PE $20 \mathrm{~g}\left(80^{\circ} \mathrm{C}, 90 \mathrm{~s}\right)$ & $\begin{array}{c}5.9 \\
(5.4-6.4) \\
\end{array}$ & $\begin{array}{c}11.6 \\
(10.7-12.5) \\
\end{array}$ & $\begin{array}{c}4.3 \\
(3.7-4.9) \\
\end{array}$ & $\begin{array}{c}2.3 \\
(2.0-2.6) \\
\end{array}$ & $\begin{array}{c}1.6 \\
(1.3-1.9) \\
\end{array}$ & $\begin{array}{c}155 \\
(122-188) \\
\end{array}$ \\
\hline ME $18 \mathrm{~g}\left(80^{\circ} \mathrm{C}, 90 \mathrm{~s}\right) \dagger$ & $\begin{array}{c}5.9 \\
(5.5-6.3) \\
\end{array}$ & $\begin{array}{c}10.8 \\
(10.1-11.5)\end{array}$ & $\begin{array}{c}5.0 \\
(4.6-5.4) \\
\end{array}$ & $\begin{array}{c}2.4 \\
(2.2-2.6) \\
\end{array}$ & $\begin{array}{c}2.1 \\
(1.8-2.4) \\
\end{array}$ & $\begin{array}{c}169 \\
(144-194)\end{array}$ \\
\hline $\begin{array}{l}\text { ME } 20 \mathrm{~g}, \\
\left(80^{\circ} \mathrm{C}, 90 \mathrm{~s}\right) \dagger\end{array}$ & $\begin{array}{c}5.3 \\
(5.0-5.6)\end{array}$ & $\begin{array}{c}11.0 \\
(10.5-11.5)\end{array}$ & $\begin{array}{c}4.7 \\
(4.4-5.0)\end{array}$ & $\begin{array}{c}2.0 \\
(2.0-2.0)\end{array}$ & $\begin{array}{c}1.6 \\
(1.3-1.9)\end{array}$ & $\begin{array}{c}143 \\
(126-160)\end{array}$ \\
\hline
\end{tabular}

${ }^{*}$ In $\mathrm{mm}$ and ${ }^{* *}$ in $\mathrm{mm}^{3}$. Confidence interval (CI 95\%) in parenthesis for $\mathrm{n}=10$, except for $\dagger$ where $\mathrm{n}=12$ as the mean of 6 measurements done using a Kimberly-Clark generator and 6 using a Stryker generator (which were not significantly different to each other). 


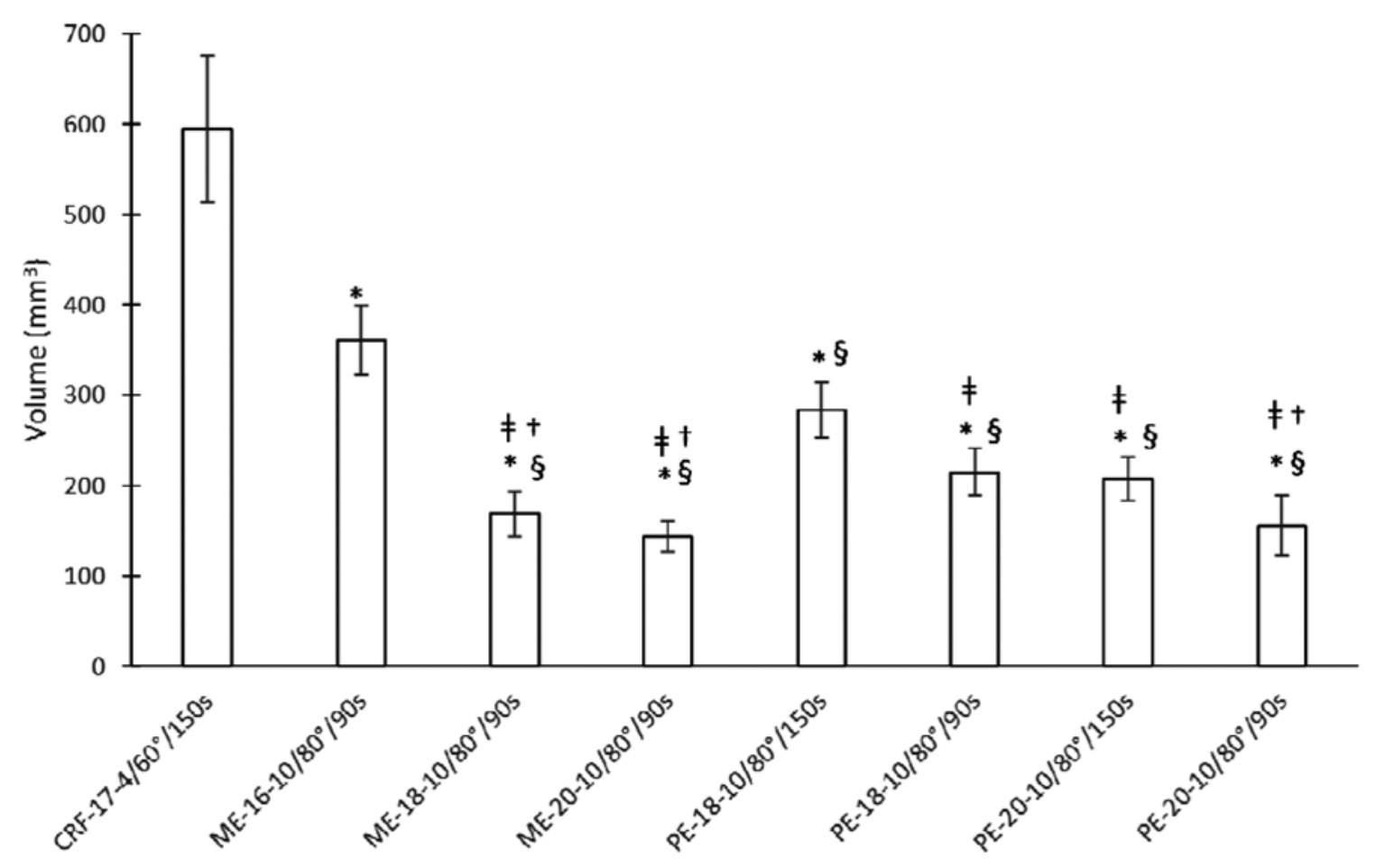

Fig. 4. Bar graph illustrating the mean lesion volumes (error bars are CI-95\%). Marks above bars indicate statistically significant

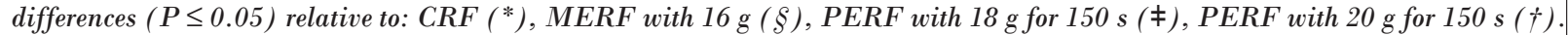
CRF-17-4 stands for CRF with $17 \mathrm{~g}, 4 \mathrm{~mm}$ tip, ME-16-10 for MERF with $16 \mathrm{~g}, 10 \mathrm{~mm}$ tip, PE-18-10 for PERF with $18 \mathrm{~g}, 10 \mathrm{~mm}$ tip, and so forth.

standard lesioning program in the Stryker generator and lasts about 15 seconds.

\section{Discussion}

The results indicate that the lesion obtained with CRF ablation at a tip temperature of $60^{\circ} \mathrm{C}$ and $150 \mathrm{sec}-$ onds is significantly larger than lesions obtained with using either ME probes under typical conditions used in clinical applications (i.e., $80^{\circ} \mathrm{C}$ for 90 seconds, $16 \mathrm{~g}$, $18 \mathrm{~g}$, or $20 \mathrm{~g}, 10 \mathrm{~mm}$ tips). The volume of CRF lesions were 1.7, 3.5, and 4.1 times larger than those obtained with MRF using $10 \mathrm{~mm}$ long tips with $16 \mathrm{~g}, 18 \mathrm{~g}$, and 20 $\mathrm{g}$ diameter, respectively. The utilization of a PE tends to increase the size of the lesion relative to the lesion using MRF, but it was found that the increase (27\%) was only significant when using an $18 \mathrm{~g}$ tip. Extending the lesioning time from 90 seconds to 150 seconds when using a PE probe had a significant effect on lesion size. For instance, the lesion increased by $32 \%$ and $34 \%$ for $18 \mathrm{~g}$ and $20 \mathrm{~g}$ probes, respectively. The effect of lesioning time has already been reported in previous work for
MRF $(12,14)$, and has not been explored further here. The increases observed in the PERF case are likely to be caused via similar effects.

The largest difference in lesion size is due to the spherical volume obtained using CRF in contrast to the ellipsoidal shaped volume obtained with both PERF and MRF. The lesion obtained with the PE probes tend to be ovoid, as the PE extends the lesion in the distal portion relative to the one obtained with a monopolar probe. Thermographic IR imaging as well as visual recording of the lesions (Fig. 6) reveal that CRF provides a symmetrical propagation of heat, while RF without cooling the tip induces spreading of the lesion in the neighborhood of the tip. As previously demonstrated by us and others, the visual appearance of a lesion correlates well with a tissue temperature above $55^{\circ} \mathrm{C}(15,16)$.

Furthermore, the propagation of the lesion in CRF occurs distally and symmetrically along the 3-dimensional lengths $(L, T, D)$. The propagation of the lesion in PERF and MRF occurs mostly along 2 dimensions (T, D), being slower longitudinally (L). Indeed, it has previously 


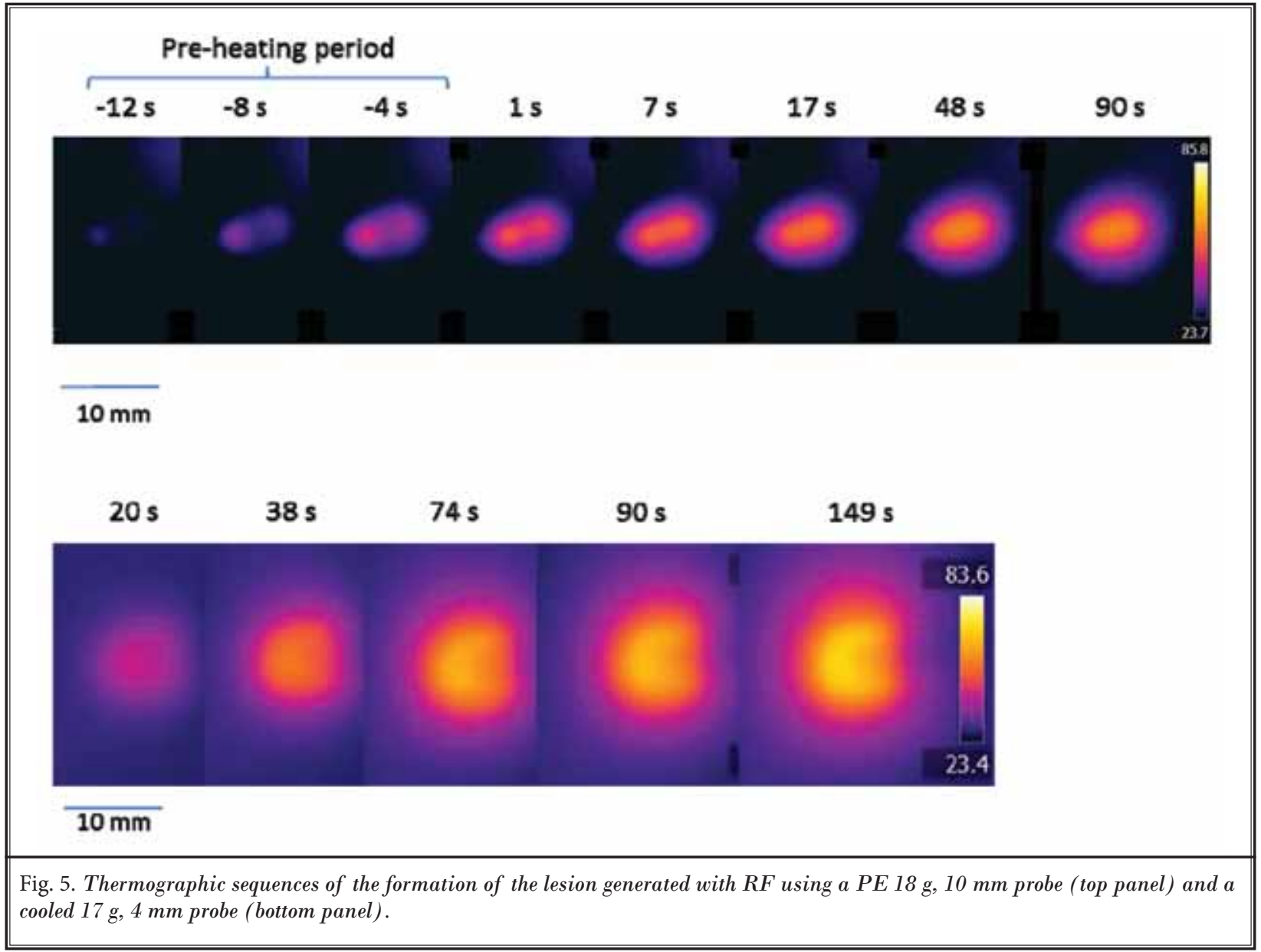

been reported that the propagation in the $\mathrm{T}$ direction is about 1.6 times more pronounced than in the $L$ direction during MRF lesioning (12). This is also illustrated in the distal lengths reported in Table 1. The lengths from the cannula to the transverse and longitudinal edges (DTC and DLC) of the visual lesion are significantly larger (by more than $1.5 \mathrm{~mm}$ ) in the CRF lesions than the ones in the larger lesions obtained with either PERF or MRF.

It is well known that the size of the lesion produced using MRF is directly proportional to the length of the active tip. For instance, an increase of $5 \mathrm{~mm}$ in the tip length causes an increase of about $5 \mathrm{~mm}$ in the $L$ of an MRF lesion (12). Consequently, the lesion produced by either MRF or PERF using a $4 \mathrm{~mm}$ active tip would be about $6 \mathrm{~mm}$ shorter in longitudinal than the one using a $10 \mathrm{~mm}$ tip, which means that the volume of the lesion would be also smaller (about $50 \%$ based on reported parametric equations). It is noteworthy to emphasize that the length of the active tip of a CRF probe is $4 \mathrm{~mm}$, yet the lesion volume is much larger than what would be expected for its monopolar equivalent.

The increase in tip diameter during a lesion using PERF increases significantly $(P<0.005)$ the lesion volume. The increase in outer diameter in going from 20 $\mathrm{g}$ to $18 \mathrm{~g}$ is $0.36 \mathrm{~mm}$, thus an increase in the $T$ and $D$ is expected. Our measurements indicate that the mean of these lengths is $0.8-1.0 \mathrm{~mm}$ longer when using the 18 $\mathrm{g}$ probe, while the increase in $\mathrm{L}$ is minimal $(0.1 \mathrm{~mm})$.

Interestingly, the mean volume obtained with a 16 g MRF is $21 \%$ larger than the one obtained with the largest commercially available PERF needle (18 g). Although the difference may be attributed to the larger diameter of the active tip in MRF, it is striking that using a simple alternative like a $16 \mathrm{~g}$ needle may create a larger lesion than the double lesion formed by the PERF.

CRF allows for quasi-spherical lesion propagation as time increases (Figs. 5 and 6), which is the main advantage of the cooled system. The cooling of the tip 


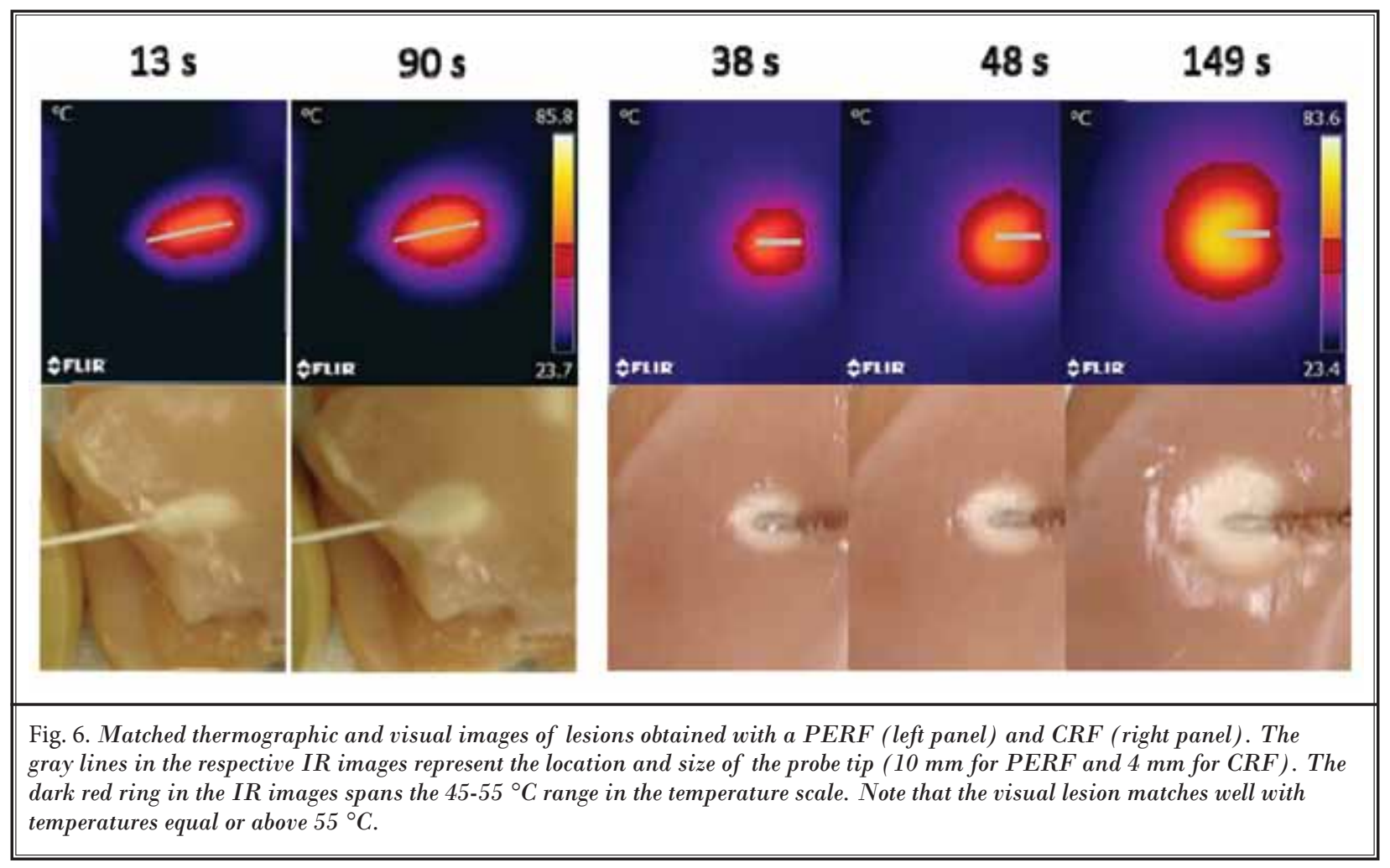

prevents the fast coagulation of the tissue around the probe, and allows for more efficient heat transfer and lesioning beyond the tip's most proximal surrounding region $(9,15)$.

The instrument used to generate the PERF lesion has a pre-warming period in which its output power is ramped up until the temperature of the probe reaches the set value $\left(80^{\circ} \mathrm{C}\right)$. Once the temperature is reached, the power is kept almost constant to lesion for a set time (90 or 150 seconds). Thermographic imaging (Fig. 5) reveals that during the warming period, the PERF system seems to generate heat at 2 "points" initially, and then this propagates in between these 2 points, in a fashion similar to a bipolar mode. This also illustrates that most of the lesion during PERF is generated early (within 20 seconds) and that the additional time allows for slower propagation mostly in the transverse length and depth. Previous studies have demonstrated that the heating (i.e., lesioning) rate in MRF and bipolar RF is much larger at early lesioning and thus the ablation tends to occur early and around the active tip $(15,16)$. Cooling of the tip, on the other hand, controls the rate of heat transfer around the tip in such a way that maximum heat (around $80^{\circ} \mathrm{C}$ ) is reached at around $2.5 \mathrm{~mm}$ from the cooled tip (15).
The main limitation of this study, however, is that does not take into account the dynamic effects that are inherent to applying the therapy in a living organism. The heterogeneous nature of the anatomy and variability of the locations in which targeted nerves may not yield lesions with shapes that are as symmetrical due to heterogeneous propagation of these (9).

\section{Conclusions}

Ex vivo lesions produced with the cooled-RF system $\left(17 \mathrm{~g}, 4 \mathrm{~mm}\right.$ active tip) at $60^{\circ} \mathrm{C}$ for 150 seconds were significantly larger than those produced by RF with a PE either with an $18 \mathrm{~g}$ or $20 \mathrm{~g}, 10 \mathrm{~mm}$ active tip at $80^{\circ} \mathrm{C}$ for 150 seconds. They were also significantly larger than those produced by MRF at $80^{\circ} \mathrm{C}$ for 90 seconds using a $16 \mathrm{~g}, 10 \mathrm{~mm}$ active tip. Lesions produced using MRF with a $16 \mathrm{~g}, 10 \mathrm{~mm}$ active tip are significantly larger than those obtained with PRF using an $18 \mathrm{~g}, 10 \mathrm{~mm}$ active tip at $80^{\circ} \mathrm{C}$ for $150 \mathrm{sec}-$ onds. However, lesions obtained using PRF are larger than those obtained with MRF using introducers of equivalent size. Lesion propagation patterns were different. A cooled active tip induces the formation of spherical lesions that project symmetrically from it, while a MRF produces an ellipsoid lesion that propa- 
gates rapidly around the tip, but slower in a longitudinal direction. Thermographic imaging reveals that the protruding electrode provides an additional heat source and the formation of the lesion resembles that of a bipolar lesion during the early stage of lesioning.

\section{References}

1. Kirschner M. Zur elektrochirurgie. Langenbecks Arch Kiln Chir 1931; 167:761-768.

2. Maas ET, Ostelo RW, Niemisto L, Jousimaa J, Hurri H, Malmivaara A, van Tulder MW. Radiofrequency denervation for chronic low back pain. Cochrane Database Syst Rev 2015; 10:CDoo8572.

3. Manchikanti L, Hirsch JA, Kaye AD, Boswell MV. Cervical zygapophysial (facet) joint pain: Effectiveness of interventional management strategies. Postgrad Med 2016; 1281:54-68.

4. Leggett LE, Soril LJ, Lorenzetti DL, Noseworthy T, Steadman R, Tiwana S, Clement F. Radiofrequency ablation for chronic low back pain: A systematic review of randomized controlled trials. Pain Res Manag 2014; 195:e146-e153.

5. Poetscher AW, Gentil AF, Lenza M, Ferretti $M$. Radiofrequency denervation for facet joint low back pain: A systematic review. Spine (Phila Pa 1976) 2014; 3914:E842-E849.

6. Van Zundert J, Vanelderen P, Kessels A, avan Kleef $M$. Radiofrequency treatment of facet-related pain: Evidence and controversies. Curr Pain Headache Rep 2012; 161:19-25.

7. Choi WJ, Hwang SJ, Song JG, Leem JG Kang YU, Park PH, Shin JW. Radiofrequency treatment relieves chronic knee osteoarthritis pain: A double-blind randomized controlled trial. Pain 2011; 1523:481-487.

8. Sluijter M, Racz G. Technical aspects of radiofrequency. Pain Pract 2002; 23:195-200.

9. Ball RD. The science of conventional and water-cooled monopolar lumbar radiofrequency rhizotomy: An electrical engineering point of view. Pain Physician 2014; 172:E175-E211.

10. Bogduk N, Macintosh J, Marsland A. Technical limitations to the efficacy of radiofrequency neurotomy for spinal pain. Neurosurgery 1987; 204:529-535.

11. McDonald GJ, Lord SM, Bogduk N. Long-term follow-up of patients treated with cervical radiofrequency neurotomy for chronic neck pain. Neurosurgery 1999;
451:61-67; discussion 67-68.

12. Cosman ER Jr, Dolensky JR, Hoffman RA. Factors that affect radiofrequency heat lesion size. Pain Med 2014; 1512:2020-2036.

13. Alberts WW, Wright EW Jr, Feinstein B, Von Bonin G. Experimental radiofrequency brain lesion size as a function of physical parameters. J Neurosurg 1966; 254:421-423.

14. Provenzano DA, Watson TW, Somers $D L$. The interaction between the composition of preinjected fluids and duration of radiofrequency on lesion size. Reg Anesth Pain Med 2015; 402:112-124.

15. Vallejo R, Benyamin R, Tilley DM, Kelley CA, Cedeno DL. An ex vivo comparison of cooled-radiofrequency and bipolarradiofrequency lesion size and the effect of injected fluids. Reg Anesth Pain Med 2014; 394:312-321.

16. Cosman ER Jr, Gonzalez CD. Bipolar radiofrequency lesion geometry: Implications for palisade treatment of sacroiliac joint pain. Pain Pract 2011; 111:3-22. 